\title{
Assessing Viability of Prevariety Germplasm of Native Coreopsis Species
}

\author{
Jeffrey G. Norcini ${ }^{1}$ and James H. Aldrich \\ University of Florida/Institute of Food and Agricultural Sciences, North \\ Florida Research \& Education Center, 155 Research Road, Quincy, \\ FL 32351 \\ Additional index words. Coreopsis basalis, Coreopsis floridana, Coreopsis lanceolata, \\ Coreopsis leavenworthii, tetrazolium, germination
} the pregermination tetrazolium test to assess whether seeds of premium-priced, prevariety germplasm of native wildflower species are living and have the potential to germinate and develop normally under field conditions, that is, whether seeds are viable. A major concern is the limited amount of industrywide training on how to conduct and interpret results of tetrazolium (TZ) tests for the multitude of native species. Precise methods that yield uniform results are especially critical for testing of prevariety germplasm of native species given their high value and economic consequences of inaccurate test results. In preliminary work, we observed that embryos extracted from intact seeds of native Coreopsis species subjected to $\mathrm{TZ}$ testing were viable if they were turgid and appeared normal and were stained pink, red, or were pure white with or without the radicle tip stained pink to red. In this study, we conducted an in-depth analysis of $\mathrm{TZ}$ testing of intact seeds of prevariety germplasm of four native Coreopsis species to: 1) verify our preliminary conclusions; and 2) to determine if staining could be improved by preconditioning or gibberellic acid $\left(\mathrm{GA}_{3}\right)$ because relatively low percentages of embryos of intact seeds stained pink or red. In addition, we evaluated two other methods to assess viability: the excised embryo test and emergence tests in soil and a soilless medium under ambient conditions. We confirmed that embryos extracted from intact seeds subjected to $\mathrm{TZ}$ testing were viable provided that embryos were turgid and appeared normal and were stained pink, red, or were pure white \pm a pink to red radicle tip. Embryo staining was not consistently improved by moist preconditioning or $\mathbf{G A}_{3}$. Results of pregermination TZ tests of intact seeds and/or germination plus postgermination $T Z$ tests of intact, nongerminated seeds were not consistently accurate and/or uniform across all species and seed lots, issues usually encountered in seed lots that were relatively dormant or of poor quality, and in postgermination TZ testing of seed lots with relatively low dormancy. Moreover, these issues are likely to be encountered even with standard TZ testing protocols given the widely accepted challenges of accurately interpreting $\mathrm{TZ}$ tests of native species in general. The most precise, uniform method of assessing viability was the excised embryo germination test because all viable seeds germinated, results were easy to interpret so the likelihood of false-positives or -negatives was nil, and results were very uniform across replications. Emergence tests under ambient conditions substantially underestimated viability. In summary, the high cost of prevariety germplasm seeds of native Coreopsis species, inherent genetic and phenotypic variability, and unknown dormancy characteristics warrant the use of the embryo excision test for determining viability and for increased sample sizes, especially for any tests involving $\mathrm{TZ}$.

Growing demand for premium value, prevariety germplasm of site or regionally specific ecotype seeds of native forbs (hereafter referred to as wildflowers) for use in ecological restoration, reclamation, and

\footnotetext{
Received for publication 6 Mar. 2008. Accepted for publication 17 June 2008 .

This project was partially funded by the Florida Wildflower Foundation (formerly known as the Florida Wildflower Advisory Council), to whom we are most grateful.

In addition, we thank Ramon Littell for his assistance with the statistical analyses and Barron Riddle, Amanda Brock, and Rebecca Riddle for their technical assistance.

${ }^{1}$ To whom reprint requests should be addressed; e-mailwldflowr@ufl.edu
}

along roadsides has resulted in a concomitant rise in seed production. Cost of these seeds is typically $\$ 110$ to $\$ 220$ per kilogram and often more for species of limited quantity and those that were manually harvested. Seeds of such prevariety germplasm are mainly produced in the midwestern and western United States (Booth and Jones, 2001; Houseal and Smith, 2000), Pennsylvania, Maryland, and Florida. Unlike seeds of domesticated flower, vegetable, and agronomic crops, moderate to substantial dormancy is common among seeds of prevariety germplasm of native wildflowers.

Seed dormancy can vary within a species and by seed origin (Andersson and Milberg, 1998; Baskin and Baskin, 1998) and harvest season (Norcini et al., 2004, 2006). Moreover, relatively broad genetic and/or pheno- typic diversity of prevariety germplasm (Czarnecki et al., 2007) usually translates into uneven flowering and ripening so seeds likely mature under different environmental conditions. Seed maturation environment affects germination and dormancy characteristics (Fenner, 1991; Roach and Wulff, 1987) and hence methods that can effectively alleviate dormancy and promote germination.

Seed dormancy presents a major challenge to those producing, testing, and using seeds of prevariety germplasm because it affects the assessment of seed quality and hence value to the producer and the amount purchased by the end user. Seed quality of prevariety germplasm of native species is based on two percentages - purity (by weight) and viability - which are used to calculate the percentage of living (hereafter referred to as viable) seeds in a seed lot, a percentage termed pure live seed (PLS). From a producer/user perspective, viable seeds are those that have been classified by testing to have the potential to germinate, emerge, and develop normally under field conditions. The PLS standard is widely used in native seed commerce because PLS allows quality among seed lots to be compared.

Methods used to determine viability vary among seed testing laboratories. To assess the total percentage of viable seeds, some laboratories rely only on germination tests (R. Wynia and V. Vankus, personal communication), which can be problematic. The inherent and potentially variable dormancy of prevariety germplasm seeds coupled with the limited number of official protocols for breaking dormancy and assessing germination of many native species means that laboratories use protocols of closely related species or use a general protocol designed for native species. As a result, the actual percentage of viable seeds can be substantially underestimated because the viability of nongerminated seeds is not assessed and the germination protocol might have not been optimal. Seed lots are then undervalued, which affects the producer, and end users must purchase more seeds than might be necessary. To assess whether nongerminated seeds are viable, many laboratories use the tetrazolium (TZ) test. Use of the TZ test has mirrored the increase in production and use of prevariety germplasm of native herbaceous species because the TZ test only determines whether an embryo is viable and the test is unaffected by the seed dormancy state except in rare cases (Vivrette, 1995). Dehydrogenase enzymes in respiring tissue reduce the colorless 2,3,5-triphenyl tetrazolium chloride to the insoluble red formazan (Lakon, 1942). A seed subjected to TZ testing is classified as viable if the embryo of the imbibed seed is turgid, and tissues/structures essential for germination and normal seedling development appear normal and are stained pink to red. For Asteraceae species, the cotyledons and radicle are the essential embryo structures evaluated for staining [Association of Official Seed Analysts (AOSA), 2000]. 
The $\mathrm{TZ}$ test is conducted in the dark using a $0.1 \%$ or $1 \%$ solution with the optimal $\mathrm{pH}$ between 6 and 7 (AOSA, 2000). The higher percentage solution is used for intact seeds to compensate for the seedcoat potentially slowing or otherwise limiting absorption. Testing can be conducted at room temperature, but increasing the temperature can speed up the staining reaction thereby reducing the time required for testing (AOSA, 2000). Staining of seeds with low metabolic rates can be enhanced by preconditioning seeds with gibberellic acid $\left(\mathrm{GA}_{3}\right)$ at 400 $\mathrm{mg} \cdot \mathrm{L}^{-1}$ (Vivrette, 1995); otherwise, viable seeds might yield a false-negative. To ensure that the TZ solution comes in contact with the embryo, seeds with coverings considered impervious to the $\mathrm{TZ}$ solution are cut or punctured (AOSA, 2000). However, cutting seeds can be a labor-intensive, intricate task, especially for small-seeded species. For example, AOSA protocols call for achenes of several Asteraceae genera to be cut laterally through the cotyledonary end to ensure that the TZ solution contacts the embryo (AOSA, 2000). In a commercial laboratory, the seed technologist must quickly identify the cotyledonary end and then orient each seed so that the proper cut can be made. After the staining period, Asteraceae embryos are extracted to examine the staining pattern and determine whether they are turgid and appear normal. For some Asteraceae, seeds stained with $\mathrm{TZ}$ are placed in a solution of lactic acid or glycerol to clear the seedcoat and examine the embryo color without extracting it (AOSA, 2000). While clearing the seedcoat can save time and prevent damage to the embryo, determining turgidity of the embryo can be difficult.

The TZ test is often conducted at the end of a germination test to determine viability of nongerminated seeds (i.e., a postgermination $\mathrm{TZ}$ test), thereby providing both the producer and end user information about germinability and the percentage of dormant seeds. However, germination and dormancy percentages are also calculated by conducting a pregermination $\mathrm{TZ}$ test concurrently with a germination test. The reasoning behind pregermination $\mathrm{TZ}$ testing is to avoid the prolonged warm, moist conditions of a germination test (essentially a stress test) that might kill at least some low-vigor seeds, thereby underestimating the total percentage of viable seeds. In preliminary pre- and postgermination $\mathrm{TZ}$ testing of intact seeds of prevariety germplasm of native Coreopsis species, we provided evidence indicating that embryos were viable if they were white, turgid, and appeared normal regardless of the degree of staining (Dehgan and Norcini, 2006; Norcini and Aldrich, 2005). Pink to red staining of the radicle tip - a site of relatively high metabolic activity - was very common. Based on those criteria for viability, percentage of viable seed values were the same when determined by pregermination $\mathrm{TZ}$ testing and germination plus a postgermination TZ test.

Determining total percentage of viable seeds using pregermination $\mathrm{TZ}$ testing is controversial, based on the argument that low-vigor seeds would not germinate, emerge, and develop normally under field conditions. The counterargument is that lowvigor seeds might play an important role in population establishment and sustainability because small, slow-growing seedlings might be less susceptible to biotic or abiotic stresses (Aarssen and Burton, 1990; Wulff, 1986). The pregermination TZ test is also run as a standalone test to determine the total percentage of viable seeds. However, with rare exception, state and federal seed laws require germination percentages on seed labels (D. Buckingham, personal communication). Labeling of prevariety germplasm seeds based solely on TZ test results is allowed only in Idaho and Nebraska (Idaho Dept. of Agriculture, 1993; Nebraska Dept. of Agriculture, Bureau of Plant Industry, 1997) and in South Dakota for two native grasses (South Dakota Statutes, 2007).

The other widely accepted test for evaluating viability of nongerminated seeds (either pre- or postgermination) is the embryo excision test (AOSA, 2004). Embryos typically are extracted from imbibed seeds and germinated under the same conditions as intact seeds of those species (Flemion, 1948). The embryo excision test, which was used before the TZ test became widely accepted in the 1960s (Gutormson, 2002), requires several days but is much shorter than a typical germination test. Heit (1947) found the embryo excision test to be an accurate method of evaluating viability of Coreopsis seeds but provided no quantitative results or details about species or methods.

Coreopsis species (coreopsis, tickseed; Asteraceae) are distributed throughout North and South America (Smith, 1975; Tadesse et al., 1995). Of the 28 Coreopsis species native to the United States (U.S. Dept. of Agriculture, Natural Resources Conservation Service, 2006), ecotype seeds of at least eight species are being commercially produced in the United States (Norcini and Aldrich, 2007). Dormancy is variable within and among freshly harvested and/or stored seeds of prevariety germplasm of native Coreopsis species produced under cultivated conditions (Kabat et al., 2007; Norcini and Aldrich, 2007; Norcini et al., 2004, 2006; Rukuni et al., 2006, 2007a).

The objectives of this study were to: 1) verify that embryos of intact Coreopsis seeds subjected to TZ testing are viable if they are turgid, appear normal, and are pure white, white with a pink radicle tip, or stained pink or red; 2) determine if $\mathrm{TZ}$ staining results of intact seeds can be improved by moist preconditioning or $\mathrm{GA}_{3} ; 3$ ) determine the accuracy of the excised embryo germination test; and 4) determine the accuracy of emergence tests for use by those that lack the laboratory facilities to conduct viability tests under controlled conditions.

\section{Materials and Methods}

Seed origin. All seeds of C. basalis, $C$. floridana, C. lanceolata, and C. leavenwor- thii were harvested from Florida ecotypes grown under cultivated conditions. Some seeds were harvested from plants growing in containers or in the field at the North Florida Research \& Education Center (NFREC) in Quincy, and some seeds were purchased from Florida growers. Purchased seeds and those harvested at the NFREC, except where noted, were stored at room temperature $\left(20\right.$ to $\left.23.9{ }^{\circ} \mathrm{C}\right)$ in the dark at $30 \%$ relative humidity $(\mathrm{RH})$ until they were used. The use of freshly harvested seeds is specifically noted with fresh seeds defined as those seeds used within 2 weeks of harvest. These seeds were dried in a desiccator ( $\approx 23 \% \mathrm{RH}$ ) at 22.2 to $25.6{ }^{\circ} \mathrm{C}$ for 2 to $10 \mathrm{~d}$ before use. Where appropriate, seed production practices, harvesting, and/or postharvest treatment of seeds are described.

General experimental and statistical analysis methods. For germination tests, seeds of all species were incubated in $100 \times$ $15-\mathrm{mm}$ petri dishes that were sealed with Parafilm ${ }^{\circledR}$ (Alcan Packaging, Nennah, WI) and contained filter paper $(\mathrm{P} 4,9.0 \mathrm{~cm}$; Fisher Scientific, Pittsburgh, PA) moistened with sterile, glass-distilled water (SDW); deviations from this protocol are noted. Seeds of all species, except $C$. lanceolata, were incubated for germination tests and moist preconditioning under an alternating temperature regime of $15 / 25^{\circ} \mathrm{C}$ (B. Dehgan, unpublished data; Kabat et al., 2007; Norcini and
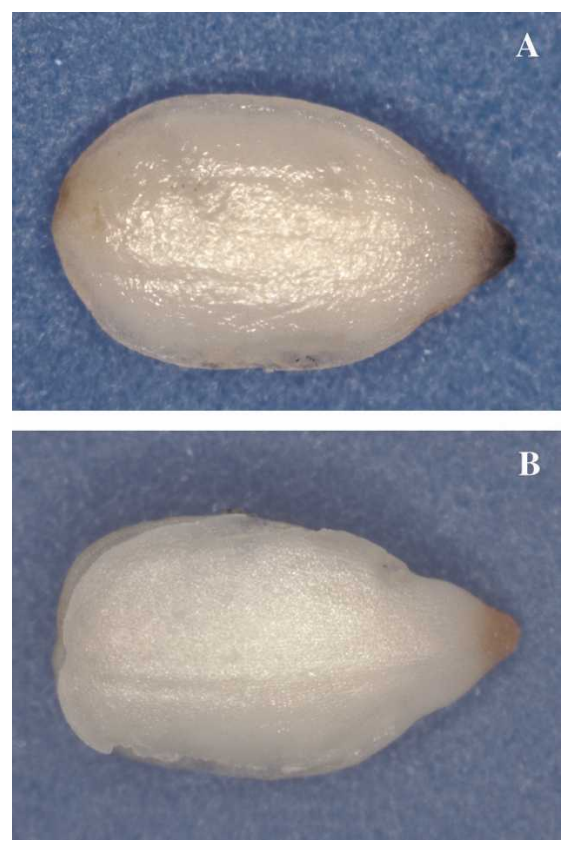

Fig. 1. Viable Coreopsis lanceolata embryos extracted from intact seeds after tetrazolium testing: (A) the embryo can easily be seen beneath the single-cell layer of endosperm (Rukuni et al., 2007b), ×40; and (B) embryo minus endosperm, $\times 30$. In both images, note that the embryos are pure white except for pink to red staining at the radicle tip. In some cases (including the other Coreopsis species), nonstained embryos might appear off-white when enclosed by the endosperm. 
Aldrich, 2005), or $20 / 30{ }^{\circ} \mathrm{C}$ for C. lanceolata (AOSA, 2004; Norcini and Aldrich, 2005), with the warmer temperature during an 8 -h photoperiod. Light during the 8-h photoperiod was provided by two $20-\mathrm{W}$ cool-white fluorescent bulbs (F20T12/CW; Osram Sylvania, Danvers, MA). A seed was deemed germinated if the radicle protruded $2 \mathrm{~mm}$ or more. Germination was recorded at 7 and 21 $\mathrm{d}$ unless otherwise noted. All germinated seeds were removed during interim counts. All TZ tests were conducted with intact seeds using $1 \% \mathrm{TZ}$ at 31 to $32{ }^{\circ} \mathrm{C}$ for $24 \mathrm{~h}$ in the dark (AOSA, 2000) unless otherwise noted.

Embryos were excised and classified as turgid with a normal appearance, nonviable based on an abnormal appearance, or lacking a visible embryo. Except where noted, the turgid, normal-appearing embryos were further classified as pure white (hereafter referred to as white), white with a pink radicle tip (Fig. 1), mostly to completely stained pink (hereafter referred to as pink), or mostly to completely stained red (with nonred portions stained pink, hereafter referred to as red). For excised embryo tests (germination and $\mathrm{TZ}$ tests), embryos were excised only from seeds that were filled

Table 1. Evaluation of methods to assess viability of stored seeds of Coreopsis basalis prevariety germplasm.

\begin{tabular}{|c|c|c|c|c|}
\hline \multirow[b]{2}{*}{ Method } & \multicolumn{2}{|c|}{ Tetrazolium test $(\%)$} & \multirow[b]{2}{*}{$\begin{array}{c}\text { Germination } \\
(\%)^{z}\end{array}$} & \multirow[b]{2}{*}{$\begin{array}{c}\text { Viable } \\
\text { seeds }(\%)^{3}\end{array}$} \\
\hline & White & $\begin{array}{c}\text { Stained white } \\
\text { with pink radicle to } \\
\text { completely red }\end{array}$ & & \\
\hline \multicolumn{5}{|l|}{ Pregerm. TZ of intact seeds } \\
\hline $30^{\circ} \mathrm{C}$ & $16.8 \mathrm{~b}^{\mathrm{x}, \mathrm{w}}(25.5)$ & $77.8 \mathrm{a}^{\mathrm{w}}(4.6)$ & - & $94.5(3.7)$ \\
\hline $35^{\circ} \mathrm{C}$ & $35.3 \mathrm{a}(2.7)$ & $55.8 \mathrm{~b}(2.3)$ & - & $91.0(1.6)$ \\
\hline $\begin{array}{l}\text { Germ. + postgerm. TZ of } \\
\text { intact seeds }\end{array}$ & $3.0 \mathrm{c}(38.5)$ & 4.5 c (66.7) & $85.0 b^{v}(4.9)$ & $92.5(4.1)$ \\
\hline $\begin{array}{l}\text { Germ. of excised embryos } \\
\text { in vitro }{ }^{u}\end{array}$ & - & - & 90.1 a $(0.2)$ & $90.1(0.2)$ \\
\hline
\end{tabular}

${ }^{2}$ Percentage germination at $21 \mathrm{~d}$ and $6 \mathrm{~d}$ for intact seeds and excised embryos, respectively.

${ }^{y}$ Percentages of viable seeds among all methods were not significantly different from each other as determined by Tukey's studentized range test $(\alpha=0.10)$.

${ }^{x}$ Means were arcsine transformed before analyses as necessary; nontransformed means are presented with coefficients of variation in parentheses.

wAny two means, within a column, not followed by the same letter are significantly different as determined by Tukey's studentized range test $(\alpha=0.01)$.

vThe two means, within this column, are significantly different as determined by Tukey's studentized range test $(\alpha=0.05)$.

"Germination on White's medium.

$\mathrm{TZ}=$ tetrazolium. (seeds that had clearly enlarged as a result of imbibition) and hence potentially viable. The presence of an underdeveloped embryo that matures during afterripening, i.e., morphological dormancy, is not known to occur in Asteraceae (Baskin and Baskin, 1998). Germination of excised embryos was recorded at $6 \mathrm{~d}$; we observed in preliminary work that viable excised embryos germinated in $6 \mathrm{~d}$ or less.

For each treatment, there were four 50 - or 100 -seed replications depending on seed availability at the time of each study.

Data for all species were analyzed separately. Percentage data were tested for homogeneity of variance and arcsine-transformed, if required, before analyses by general linear model methods of SAS (version 8.01; SAS Institute, Cary, NC). Main effects means were compared using Tukey's studentized range test $(\alpha=0.05$ or 0.01$)$. Comparisons between individual means for interactive effects were determined using least squares means analyses [LSMEANS with PDIFF option (SAS version 8.01; SAS Institute)]. Coefficients of variation $(\mathrm{CsV})$ were calculated as a measure of uniformity for staining, germination, and viability percentages. Other data analysis procedures are noted for each study.

Tetrazolium staining of intact seeds. Coreopsis basalis seeds were purchased from Wildflowers of Florida (Alachua, FL), who harvested seeds from a natural population in Alachua County, FL. The following experiments were conducted to verify that embryos excised from intact seeds subjected to TZ testing were viable if they were turgid, white, and appeared normal regardless of the degree of staining: 1) TZ test of intact seeds at 30 or

Table 2. Assessing viability of stored seeds of prevariety germplasm of native Coreopsis species: effects of presoaking intact seeds on staining, and use of excised embryos.

\begin{tabular}{|c|c|c|c|c|c|c|}
\hline \multirow[b]{2}{*}{ Method } & \multicolumn{4}{|c|}{ Tetrazolium test (\%) } & \multirow[b]{2}{*}{ Germ. at $7 \mathrm{~d}(\%)$} & \multirow[b]{2}{*}{ Viable $(\%)$} \\
\hline & White & White with pink radicle tip & Pink & Red & & \\
\hline \multicolumn{7}{|c|}{ Coreopsis basalis } \\
\hline \multicolumn{7}{|c|}{ Pregerm. TZ—intact seeds } \\
\hline 24-h soak & 0 & $86.0(6.8)$ & $6.5(46.2)$ & $3.0(86.1)$ & - & $95.5(4.3)$ \\
\hline \multicolumn{7}{|l|}{ Excised embryo } \\
\hline Pregerm. TZ & 0 & 0 & 0 & $99.0(1.2)$ & - & $99.0(1.2)$ \\
\hline Germination & - & - & - & - & 100 & 100 \\
\hline 24-h soak & $3.5(54.7)$ & $85.5(6.2)$ & $7.5(25.5)$ & $1.0(115.5)$ & - & $97.5(2.0)$ \\
\hline \multicolumn{7}{|l|}{ Excised embryo } \\
\hline Pregerm. TZ & 0 & 0 & 0 & $92.0(3.1)$ & - & $92.0 \mathrm{~b}^{\mathrm{y}}(3.1)$ \\
\hline Germination & - & - & - & - & 100 & $100 \mathrm{a}$ \\
\hline \multicolumn{7}{|c|}{ Coreopsis leavenworthii } \\
\hline Germination & - & - & - & - & 100 & $100 \mathrm{a}$ \\
\hline
\end{tabular}

${ }^{\mathrm{z}}$ Means were arcsine-transformed as necessary before analyses; nontransformed means are presented with coefficients of variation in parentheses.

${ }^{y}$ Means, within a species, column, and method, followed by different letters are significantly different as determined by Tukey's studentized range test ( $\left.\alpha=0.01\right)$. Mean separations shown are within method only (pregermination TZ and excised embryo) because only filled seeds were used for embryo excision tests, which did not include seeds that were nonviable as a result of an underdeveloped embryo or lack of an embryo. However, when analyses were conducted across methods within a species, differences among all $C$. basalis percentage viability values were nonsignificant $(\alpha=0.05)$, and for $C$. lanceolata percentage viability differences among the pregermination TZ tests and excised embryo germination test were nonsignificant $(\alpha=0.05)$.

$\mathrm{TZ}=$ tetrazolium 
$35^{\circ} \mathrm{C}$ with turgid, normal-appearing embryos excised from tested seeds classified as white or partially to completely stained; 2) germination $\left(30{ }^{\circ} \mathrm{C}, 8-\mathrm{h}\right.$ photoperiod) of intact seeds with $\mathrm{TZ}$ testing of nongerminated seeds at $30^{\circ} \mathrm{C}$ as described in $\# 1$; germination was evaluated only at $21 \mathrm{~d}$; and 3 ) germination of excised embryos $\left(30{ }^{\circ} \mathrm{C}, 8\right.$-h photoperiod) on White's medium (Sharma, 1979; White, 1963); germination was evaluated only at $6 \mathrm{~d}$. Embryos were excised from seeds that had been imbibed for $24 \mathrm{~h}$. The White's medium contained (per liter) $0.5 \mathrm{mg}$ nicotinic acid, $0.1 \mathrm{mg}$ each of thiamine and pyridoxine, $3 \mathrm{mg}$ glycine, and $1 \%(\mathrm{w} / \mathrm{v})$ sucrose and was adjusted to a $\mathrm{pH}$ of 5.7 before addition of $1 \%(\mathrm{w} / \mathrm{v})$ agar. White's medium was autoclaved $\left(20 \mathrm{~min}\right.$ at $\left.121{ }^{\circ} \mathrm{C}\right)$ before use. To conservatively verify nonsignificant differences, the alpha level for Tukey's studentized range was set at 0.10 .

Presoaking effect on tetrazolium staining of intact seeds and viability of excised embryos. Intact seeds of C. basalis, C. lanceolata, and $C$. leavenworthii were placed under running tap water $(\mathrm{pH} 8.1)$ for $24 \mathrm{~h}$ before $\mathrm{TZ}$ testing. Presoaking seeds was conducted to determine whether staining would be enhanced as a result of increased metabolic activity [or an indirect increase in metabolic activity by leaching potential water soluble inhibitors (e.g., Forsyth and Brown, 1982)]. In addition, embryos excised from a subset of seeds soaked for $24 \mathrm{~h}$ were subjected to germination and pregermination $\mathrm{TZ}$ tests.

Effects of moist preconditioning, gibberellic acid, and seed lot on tetrazolium staining. This experiment was conducted to determine whether TZ staining of embryos from two seed lots (per species) could be enhanced by subjecting intact seeds to moist preconditioning and exposure to $\mathrm{GA}_{3}$. Seeds of $C$. floridana and freshly harvested seeds of $C$. basalis, C. lanceolata, and C. leavenworthii were imbibed in petri dishes on filter paper moistened with SDW. After 24, 48, or 96 h of moist preconditioning, seeds were transferred to petri dishes containing filter paper wetted with an aqueous (SDW) solution of $\mathrm{GA}_{3}$ at $400 \mathrm{mg} \cdot \mathrm{L}^{-1}$ (Prod. No. G500; PhytoTechnology Laboratories, Shawnee Mission, $\mathrm{KS}$ ). After $24 \mathrm{~h}$ exposure to $\mathrm{GA}_{3}$, seeds were subjected to $\mathrm{TZ}$ testing. At $0 \mathrm{~h}$, seeds were subjected to pregermination $\mathrm{TZ}$ testing as well as germination plus postgermination $\mathrm{TZ}$ testing of nongerminated seeds. Seeds of each species that were derived from different lots or sources and that had been stored for 1 to 2 years (as previously described) were also included and treated similarly. Germination was evaluated at 7,14 , and $21 \mathrm{~d}$ with germinated seeds being removed at interim counts. Only total germination is reported for all treatments. To obtain an estimate of percentage viable seeds, a pregermination $\mathrm{TZ}$ test was conducted with 15 to 18 seeds (per species) that were laterally cut through the cotyledonary end, thereby directly exposing the embryo to the TZ solution (AOSA, 2000). Embryos were then excised and the staining class recorded.

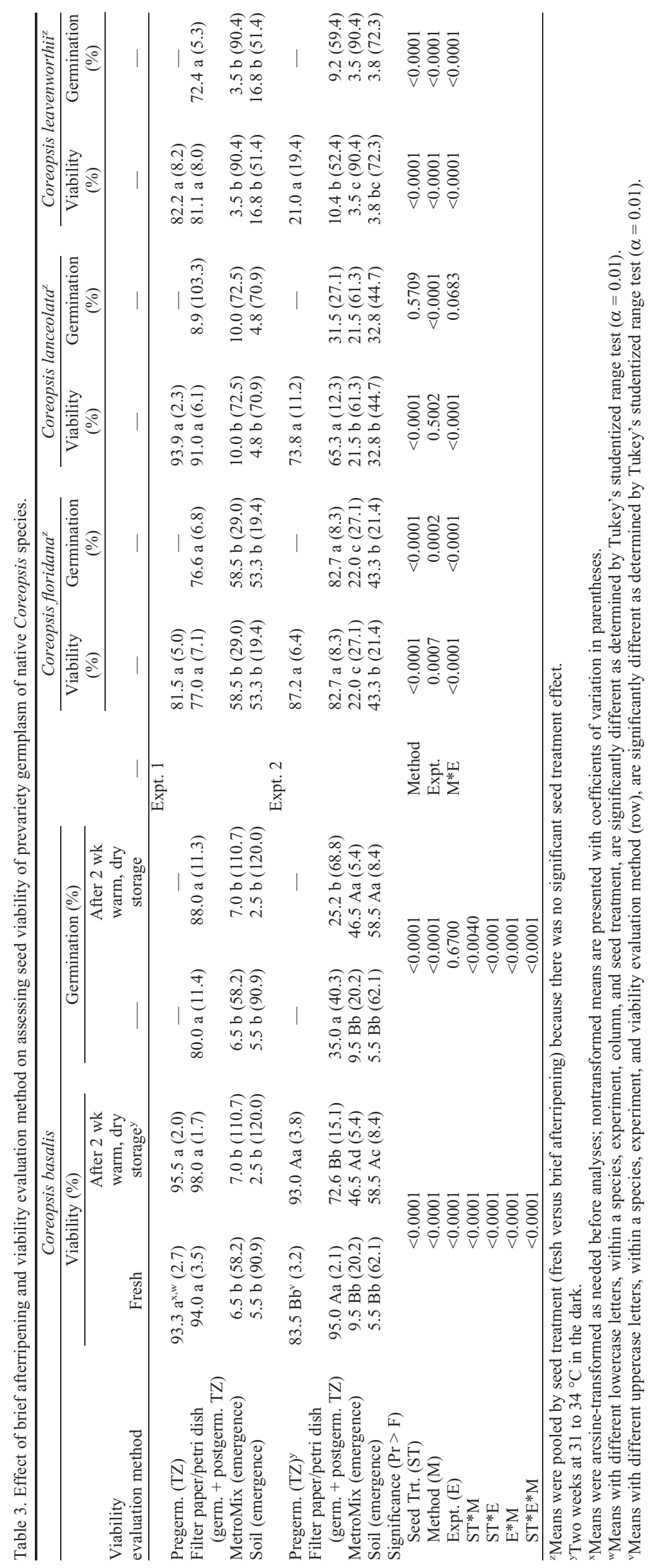

1873 
Analyses of $\mathrm{TZ}$ staining results were normalized based on percentage of viable seeds for each replication. Significant moist preconditioning effects $(P \leq 0.05)$ as well as interactions involving moist preconditioning with $P \leq 0.10$ (R. Littell, personal communication) were subjected to sequential, regression analyses. The quadratic term was included in the final model only if its inclusion was significant at $\alpha=0.05$ and the adjusted $R^{2}$ value improved by at least 0.05 . For models involving only "plus $\mathrm{GA}_{3}$ ", only linear models were evaluated. Analyses were conducted separately for each species and seed lot.

Substrate and seed storage effects on assessing viability of intact seeds. Seed producers and those that harvest their own seeds from local natural stands for restoration or mine reclamation occasionally desire to estimate the viability and germinability of their seeds. However, they typically lack the facilities to conduct such testing under controlled conditions. This experiment was conducted to determine the accuracy of viability testing that could be used by those that lack such facilities.

Seeds were harvested, half of which were placed in a desiccator $(23 \% \mathrm{RH} ; 22.8$ to $25.6{ }^{\circ} \mathrm{C}$ ) for $2 \mathrm{~d}$ and the other half afterripened in the dark for 2 weeks at 31 to $32{ }^{\circ} \mathrm{C}$ ( $35 \%$ to $37 \% \mathrm{RH})$. Subsets of 50 seeds from the desiccator were sown on field soil or Metro-Mix 200 (Sun Gro Horticulture, Bellevue, WA) in each of four pots. The field soil (Orangeburg loamy sand) was sifted (soil sieve with $1.7-\mathrm{mm}$ openings in mesh) to remove root pieces and large particles. Media was contained in square plastic pots $(8.9 \times 8.9 \times$ $8.9 \mathrm{~cm})$. Sown seeds were lightly covered with 1 to $2 \mathrm{~mm}$ of substrate, irrigated with tap water, and subsequently irrigated at least every $3 \mathrm{~d}$. Except for $C$. floridana, pots of all species were placed outdoors in the shade during mid-June to Aug. 2004. Average summer minimum and maximum temperatures are 23 and $33{ }^{\circ} \mathrm{C}$, respectively (Southeast Regional Climate Center, 2001). Pots of C. floridana were germinated under laboratory conditions $\left(20\right.$ to $24.4{ }^{\circ} \mathrm{C}$ ) because it was winter. For controls, subsets of seeds were subjected to a pregermination $\mathrm{TZ}$ test and a germination test plus a postgermination $\mathrm{TZ}$ test of nongerminated seeds. Numbers of emerged seedlings were recorded every $3 \mathrm{~d}$ over $42 \mathrm{~d}$, whereas numbers of germinated seeds incubated in petri dishes were recorded every 3 to $4 \mathrm{~d}$. Emerged seedlings and germinated seeds were removed during interim counts. Only the final total number of germinated and emerged seedlings is reported.

Afterripened seeds were subjected to the same tests as previously described. The entire study was then repeated using newly harvested seeds from the same groups of plants for each species.

\section{Results and Discussion}

Excising embryos from imbibed seeds was easiest with $C$. floridana with minimal

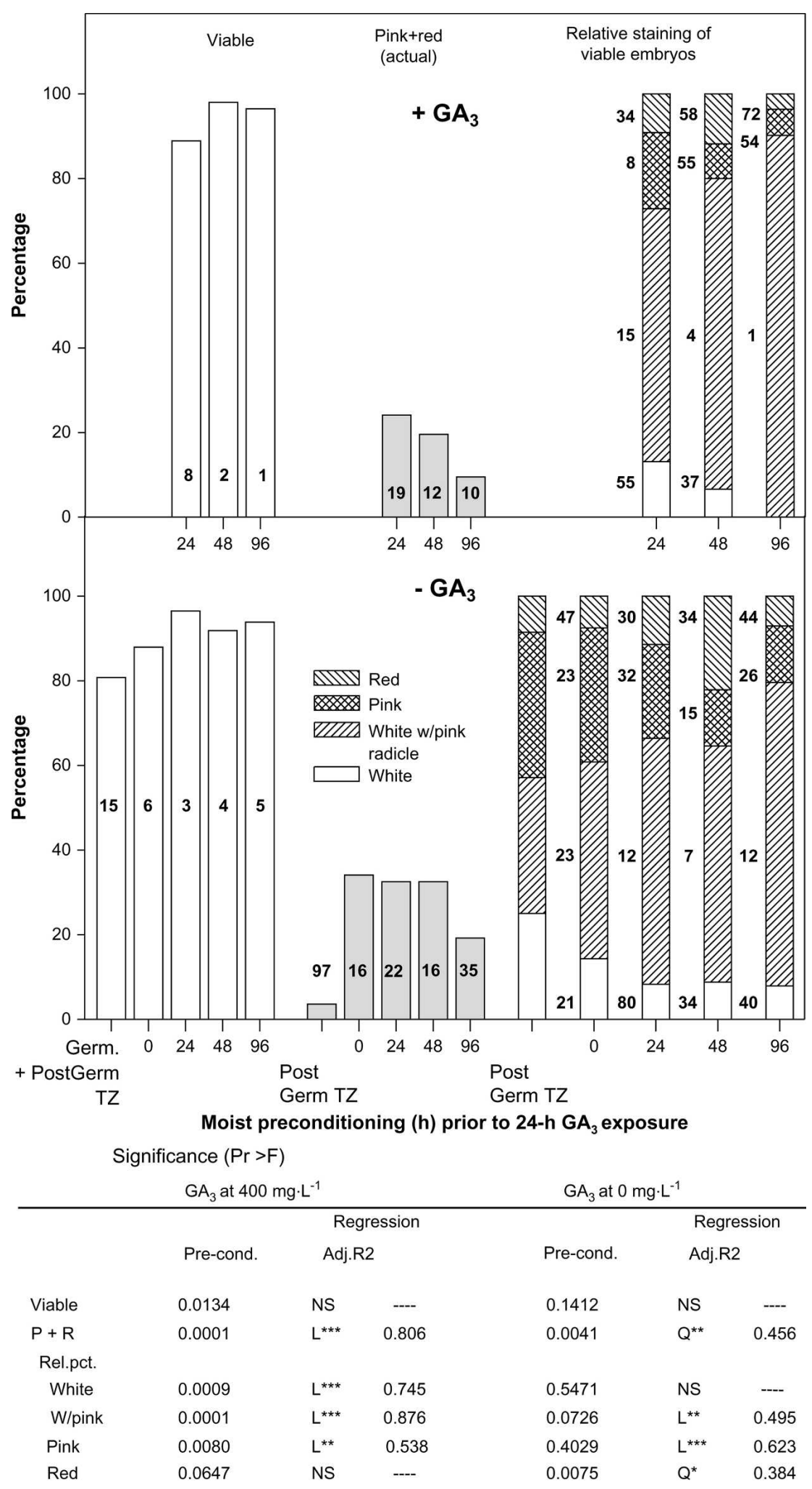

Fig. 2. Moist preconditioning (water only) and gibberellic acid $\left(\mathrm{GA}_{3}\right)$ effects on the pregermination tetrazolium (TZ) test to estimate percentage viability of fresh (less than 2 weeks after harvest), intact seeds of Coreopsis basalis. Seeds were exposed to $\mathrm{GA}_{3}$ at 0 or $400 \mathrm{mg} \cdot \mathrm{L}^{-1}$ for $24 \mathrm{~h}$ after moist preconditioning for 24,48 , or $96 \mathrm{~h}$, and then subjected to TZ testing. A germination test $(70.4 \%$; coefficient of variation $=27.3$ ) plus postgermination test of nongerminated seeds was included as a standard method of calculating percentage viability; this treatment was not included in the regression analyses. Estimated percentage viability based on a preliminary pregermination TZ test using the AOSA (2000) protocol (seeds cut through the cotyledonary end; essential tissues stained pink to red) was $94.4 \%(n=18)$. Coefficients of variation less than 100 are shown within or to the immediate left of each bar. 
skill needed to do so without damaging the embryos. More extensive skill and practice were required for excising embryos of $C$. basalis and C. lanceolata, mainly because seeds were smaller. Manipulating seeds of C. lanceolata was slightly more challenging because seeds were winged and convex/ concave (Rukuni et al., 2007b). The most difficult seeds to work with were those of C. leavenworthii. Excising the thin, delicate, linear embryos from the slightly convex/ concave, winged seeds of $C$. leavenworthii (Kabat et al., 2007) was an intricate task and required considerable skill. Embryos were easily injured, which hampered interpretation of TZ staining patterns as well as excision of embryos for extracted embryo germination tests.

Assessing viability of intact seeds using tetrazolium. Turgid, normal-appearing embryos excised from intact Coreopsis seeds subjected to $\mathrm{TZ}$ testing were viable provided that they were either white, white with just the radicle tip stained pink (Fig. 1), or stained pink to red. That white embryos and white embryos with pink radicle tips were viable was first confirmed by results with $C$. basalis seeds (Table 1). When total percentage of viable seeds subjected to TZ testing included turgid, normal-appearing embryos that were white \pm pink radicle tip, or stained pink to red, similar percentage values were obtained for a germination test plus $\mathrm{TZ}$ testing of nongerminated seeds, germination of excised embryos, and a pregermination $\mathrm{TZ}$ test. Other researchers have concluded that normalappearing, firm white embryos are viable (C. Baskin, personal communication), including those of Asteraceae (Bender et al., 2003; Ruiz de Clavijo, 2005). In follow-up studies with $C$. basalis, C. floridana, C. lanceolata, and C. leavenworthii, nearly all evidence supported the premise that embryos extracted from intact seeds subjected to $\mathrm{TZ}$ testing are viable provided that the embryos are turgid, appear normal, and are white \pm pink radicle tip or stained pink to red (Tables 2 and 3; Figs. 2-8).

For our standard pregermination TZ testing of intact seeds (i.e., no pretreatment), the greatest percentage of viable embryos extracted from $C$. basalis, $C$. lanceolata, and $C$. leavenworthii were white with a pink radicle tip (Table 2; Figs. 1-3 and 5-8). In all but one case, this percentage was 50 or greater with values ranging as high as $91.9 \%$. In contrast to the other three species, only $9.7 \%$ of viable C. floridana embryos were white with a pink radicle tip with the remainder staining pink or red. For the other three species, embryos staining pink to red constituted approximately one-third or less of viable embryos (Figs. 2, 3, and 5-8). Only a small percentage of viable embryos did not stain with values ranging from $0 \%$ to $22.7 \%$ depending on species (Table 2; Figs. 2, 3, and 5-8).

Viability percentages based on our standard pregermination $\mathrm{TZ}$ protocol were relatively uniform because $\mathrm{CsV}$ were usually 5 or less (Tables 1-3). The two highest $\mathrm{CsV}$ were

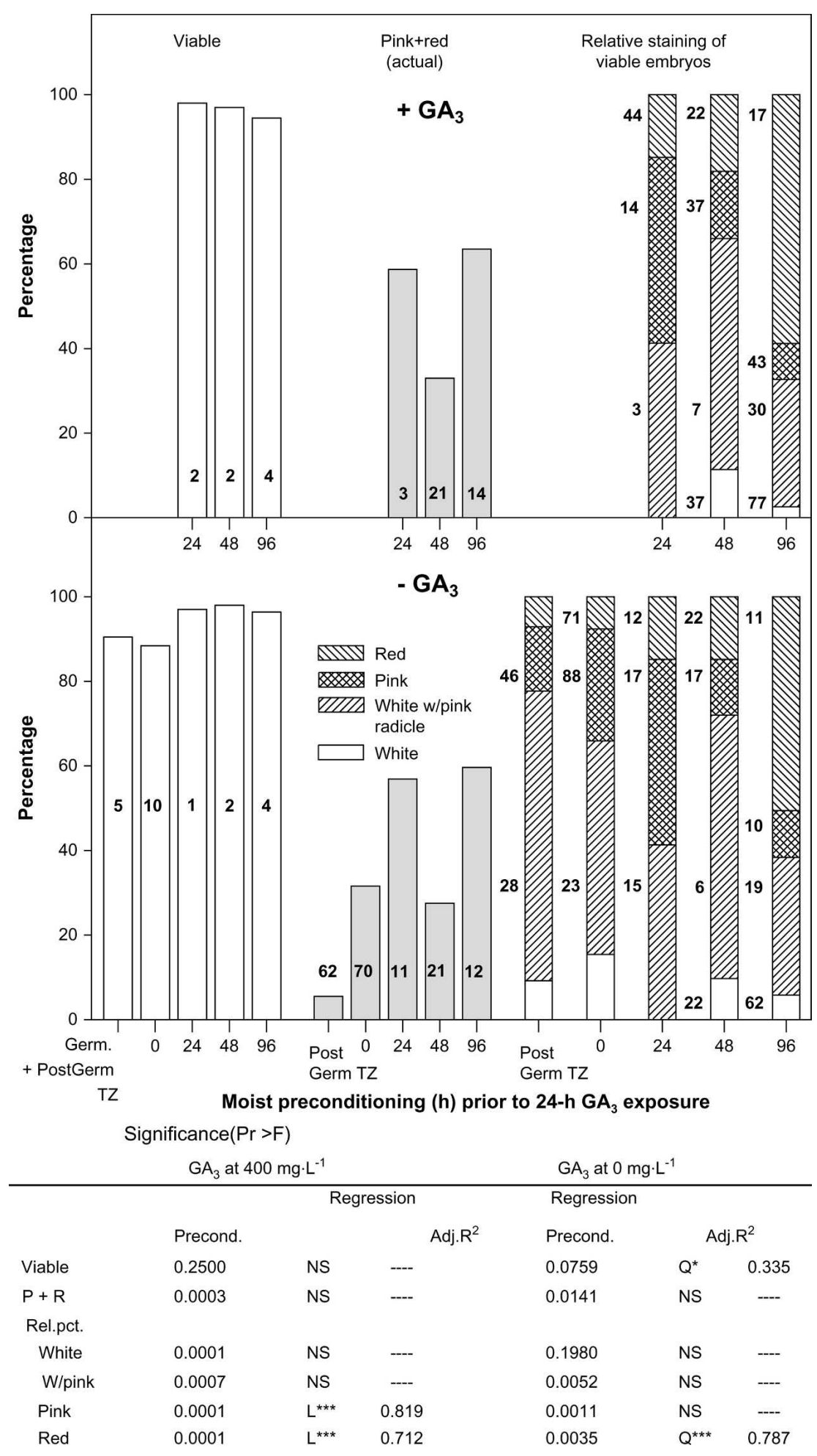

Fig. 3. Moist preconditioning (water only) and gibberellic acid $\left(\mathrm{GA}_{3}\right)$ effects on the pregermination tetrazolium (TZ) test to estimate percentage viability of stored, intact seeds of Coreopsis basalis. Seeds were exposed to $\mathrm{GA}_{3}$ at 0 or $400 \mathrm{mg} \cdot \mathrm{L}^{-1}$ for $24 \mathrm{~h}$ after moist preconditioning for 24,48 , or $96 \mathrm{~h}$, and then subjected to $\mathrm{TZ}$ testing. A germination test $(67.5 \%$; coefficient of variation $=9.8)$ plus postgermination test of nongerminated seeds was included as a standard method of calculating percentage viability; this treatment was not included in the regression analyses. Seeds were from a different lot or source than in Figure 2. Estimated percentage viability based on a preliminary pregermination TZ test using the AOSA (2000) protocol (seeds cut through the cotyledonary end; essential tissues stained pink to red) was $93.3 \%(n=15)$. Coefficients of variation less than 100 are shown within or to the immediate left of each bar. 
for C. leavenworthii-19.4 (Table 3) and 34.0 (results not shown), which was likely related to difficulties extracting embryos and interpreting staining patterns as we noted previously. In the latter case, viability percentage based on the pregermination TZ test $(21 \%)$ was substantially less than the actual viability because $53 \%$ of the seeds germinated and total viable seeds was nearly $60 \%$. Hence, TZ testing of $C$. leavenworthii intact seeds, either pre- or postgermination, might considerably underestimate the actual percentage of viable seeds, especially in seeds lots with moderate to high percentages of dormant seeds. Also, given the nature of imbibed C. leavenworthii seeds, we would expect similar challenges extracting embryos even for seeds that were cut laterally through the cotyledon before $\mathrm{TZ}$ testing (AOSA, 2000).

For the pregermination $\mathrm{TZ}$ test of intact seeds, the relative percentages of embryos that stained pink to red were not consistently improved across all seed lots of all species by: 1) increasing the incubation temperature, which reduced staining (Table 1; C. basalis only); 2) by seed pretreatments of soaking under running tap water for $24 \mathrm{~h}$ (Table 2); or 3) up to $96 \mathrm{~h}$ moist preconditioning \pm 400 $\mathrm{mg} \cdot \mathrm{L}^{-1} \mathrm{GA}_{3}$ (Figs. 2-8). Moreover, seed pretreatments did little to improve uniformity (Table 2; Figs. 2-8); within a seed pretreatment, greatest uniformity as determined by $\mathrm{CsV}$ most often occurred for the staining category with the highest percentages (Figs. $2-8)$. In only two cases did any pretreatment increase the percentages of pink + red embryos with the only significant effect being for moist preconditioning. Twentyfour hours of moist preconditioning of stored C. basalis seeds increased the relative percentage of pink + red embryos (Fig. 3). For stored seeds of $C$. lanceolata, pink + red staining was directly related to hours of moist preconditioning (Fig. 6). However, any increases in the relative percentages of embryos that stained pink to red after $96 \mathrm{~h}$ moist preconditioning was likely the result of seedcoat rupture as the radicle emerged resulting in penetration of the $\mathrm{TZ}$ solution. Radicle emergence in Coreopsis has been observed as early as $4 \mathrm{~d}$ after seeds are placed on a moistened medium (J.G. Norcini and D. Rukuni, unpublished observations).

For postgermination TZ testing of nongerminated seeds, percentages of stained embryos (red, pink, or white with a pink radicle) varied widely depending on species and seed lot and with no hint of any apparent relationship to percentage of dormant seeds. There were few or no dormant seeds of $C$. floridana. Percentages of viable, nonstained embryos varied widely with relatively low values for $C$. leavenworthii ( $0 \%$ and $8.3 \%$; Figs. 7 and 8 ) and C. basalis $(9.2 \%$ and $25 \%$; Figs. 2 and 3), but higher values for $C$. lanceolata (41.0 and 58.8\%; Figs. 5 and 6).

The widely accepted reason for the lack of staining is that the endosperm surrounding Coreopsis embryos (Rukuni et al., 2007b) and other Asteraceae (Borthwick and Robbins, 1928; Kaye, 2002) is impermeable,

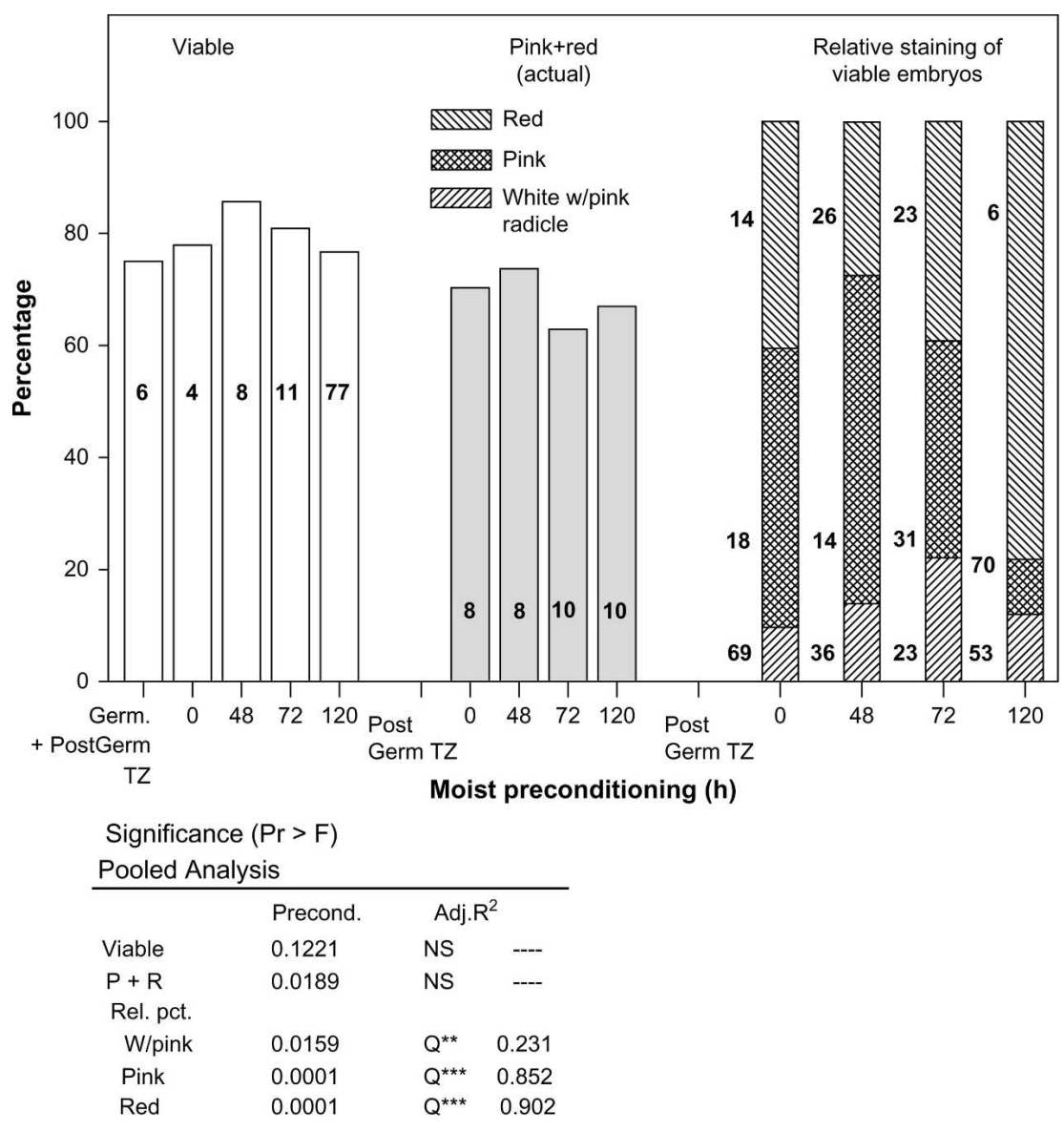

Fig. 4. Moist preconditioning (water only) and gibberellic acid $\left(\mathrm{GA}_{3}\right)$ effects on the pregermination tetrazolium (TZ) test to estimate percentage viability of stored, intact seeds of Coreopsis floridana. Seeds were exposed to $\mathrm{GA}_{3}$ at 0 or $400 \mathrm{mg} \cdot \mathrm{L}^{-1}$ for $24 \mathrm{~h}$ after moist preconditioning for 24,48 , or $96 \mathrm{~h}$, and then subjected to $\mathrm{TZ}$ testing. A germination test $(77.9 \%$; coefficient of variation $=1.4)$ plus postgermination test of nongerminated seeds was included as a standard method of calculating percentage viability; this treatment was not included in the regression analysis. Coefficients of variation less than 100 are shown within or to the immediate left of each bar.

or nearly so, to tetrazolium chloride at neutral $\mathrm{pH}$ (AOSA, 2000), although we showed that Coreopsis endosperm clearly has some permeability to $1 \% \mathrm{TZ}$ at neutral $\mathrm{pH}$ and 30 to $35^{\circ} \mathrm{C}$. Some degree of staining was observed for $77 \%$ to $100 \%$ of viable embryos of all species (Tables 1-3; Figs. 1-8). To ensure contact of the TZ solution with the embryo, the AOSA TZ protocol for Asteraceae species specifies that seeds be cut laterally or longitudinally before their exposure to the TZ solution (AOSA, 2000). Although cutting seeds overcomes the issue of $\mathrm{TZ}$ contact with Coreopsis embryos, cutting might not overcome challenges associated with accurately determining whether a seed is viable based on the staining pattern. We observed some inconsistencies based on preliminary data for seeds that were cut laterally through the cotyledon end before the TZ test with viability based on AOSA specifications for Asteraceae (AOSA, 2000) (Figs. 6 and 8). The most notable example was for stored seeds of C. leavenworthii (Fig. 8). Two of 13 embryos from seeds that were laterally cut were deemed viable $(\approx 13 \%)$ (Fig. 8$)$, although nine embryos were white with a pink radicle tip. However, germination was $53.0 \%$ with total viable seeds estimated at $57.0 \%$. Estimated percentage viable seeds based on a pregermination TZ test was $38.5 \%$, significantly less than $57.0 \%(P \leq 0.05)$.

Metabolic activity might have affected staining as well. First, a relatively high percentage of radicle tips, a site of meristematic activity, stained pink (Tables 1 and 2; Figs. 2-8). Second, a high percentage of $C$. floridana embryos stained pink or red, their dormancy was nil (Fig. 3), and C. floridana seeds have short storage life (Norcini and Aldrich, 2007), all of which is consistent for seeds having relatively high metabolic activity. Failure of $\mathrm{GA}_{3}$ at $400 \mathrm{mg} \cdot \mathrm{L}^{-1}$ to increase staining is not inconsistent with a metabolic activity effect on staining. The lack of a $\mathrm{GA}_{3}$ effect simply might have been the result of $\mathrm{GA}_{3}$ concentration. Gibberellic acid at 0.1 to $100 \mu \mathrm{M}\left(400 \mathrm{mg} \cdot \mathrm{L}^{-1} \cong 1 \mu \mathrm{M} \mathrm{GA}_{3}\right)$ had little effect on germination of $C$. lanceolata, whereas germination of $C$. floridana only was enhanced by $\mathrm{GA}_{3}$ at 10 to $100 \mu \mathrm{M}$ (D. Rukuni, unpublished data). Percent germination and germination velocity of $C$. basalis seeds was increased by $\mathrm{GA}_{3}$ but at $1000 \mathrm{mg} \cdot \mathrm{L}^{-1}$ (lower concentrations not tested) (Carpenter and Ostmark, 1992, 2007). Seed coat permeability 


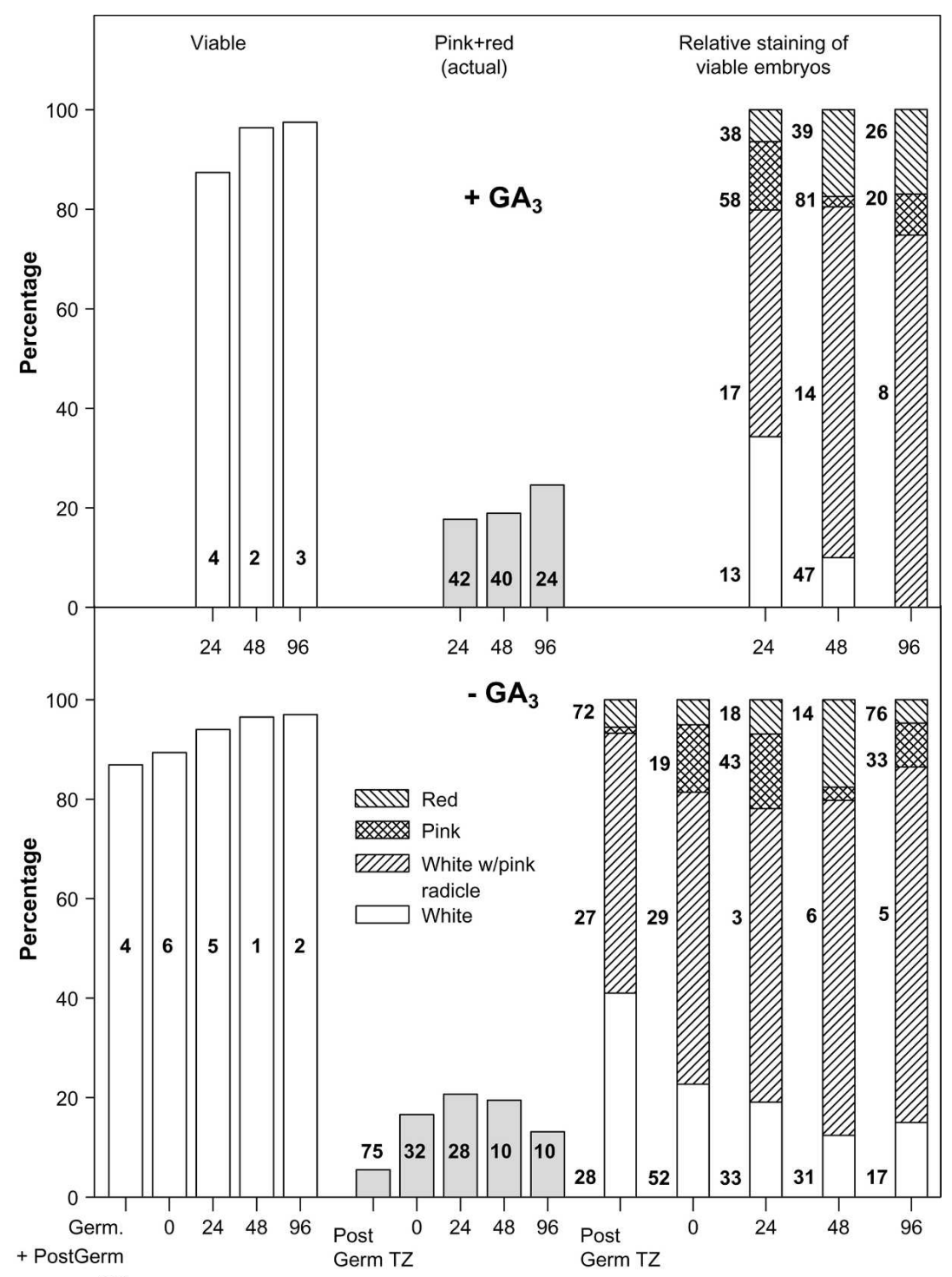

$\mathrm{TZ} \quad$ Moist preconditioning (h) prior to $24-\mathrm{h} \mathrm{GA}_{3}$ exposure

Significance $(\mathrm{Pr}>\mathrm{F})$

\begin{tabular}{|c|c|c|c|c|c|c|}
\hline \multirow[b]{4}{*}{ Viable } & \multicolumn{3}{|c|}{$\mathrm{GA}_{3}$ at $400 \mathrm{mg} \cdot \mathrm{L}^{-1}$} & \multicolumn{3}{|c|}{$\mathrm{GA}_{3}$ at $0 \mathrm{mg} \cdot \mathrm{L}^{-1}$} \\
\hline & \multicolumn{3}{|c|}{ Regression } & \multicolumn{3}{|c|}{ Regression } \\
\hline & Precond. & \multicolumn{2}{|c|}{ Adj. $R^{2}$} & Precond. & \multicolumn{2}{|c|}{ Adj. $R^{2}$} \\
\hline & 0.0081 & $L^{\star *}$ & 0.580 & 0.0687 & $L^{* *}$ & 0.366 \\
\hline$P+R$ & 0.3720 & NS & --- & 0.0723 & $Q^{*}$ & 0.341 \\
\hline \multicolumn{7}{|l|}{ Rel.pct. } \\
\hline White & 0.0001 & $L^{* * *}$ & 0.949 & 0.2585 & NS & --- \\
\hline W/pink & 0.0012 & $\mathrm{~L}^{* *}$ & 0.636 & 0.1868 & $L^{*}$ & 0.233 \\
\hline Pink & 0.0089 & NS & --- & 0.0015 & NS & ---- \\
\hline Red & 0.0106 & $L^{*}$ & 0.420 & 0.0036 & $Q^{*}$ & 0.330 \\
\hline
\end{tabular}

Fig. 5. Moist preconditioning (water only) and gibberellic acid $\left(\mathrm{GA}_{3}\right)$ effects on the pregermination tetrazolium (TZ) test to estimate percentage viability of fresh (less than 2 weeks after harvest), intact seeds of Coreopsis lanceolata. Seeds were exposed to $\mathrm{GA}_{3}$ at 0 or $400 \mathrm{mg} \cdot \mathrm{L}^{-1}$ for $24 \mathrm{~h}$ after moist preconditioning for 24,48 , or $96 \mathrm{~h}$, and then subjected to $\mathrm{TZ}$ testing. A germination test $3.0 \%$; coefficient of variation $=115.5$ ) plus postgermination test of nongerminated seeds was included as a standard method of calculating percentage viability; this treatment was not included in the regression analyses. Estimated percentage viability based on a preliminary pregermination TZ test using the AOSA (2000) protocol (seeds cut through the cotyledonary end; essential tissues stained pink to red) was $92.3 \%(n=13)$. Coefficients of variation less than 100 are shown within or to the immediate left of each bar. to $\mathrm{GA}_{3}$ might also have been a factor. For example, germination of Parthenium argentatum Gray (Asteraceae) was enhanced more by $\mathrm{GA}_{3}\left(200 \mathrm{mg} \cdot \mathrm{L}^{-1}\right)$ when seeds were scarified for $2 \mathrm{~h}$ in sodium hypochlorite compared with nonscarified seeds treated with $\mathrm{GA}_{3}$ (Naqvi and Hanson, 1980). The inability of moist preconditioning or soaking seeds in running tap water to improve staining also is consistent with a metabolic activity effect on staining. The pericarp, testa, and/ or endosperm simply might have been impermeable to metabolic inhibitors in the embryo, inhibitors that could leach when seeds are cut before TZ testing. Germination inhibitors commonly occur in cotyledons of Asteraceae seeds (Intl. Board for Plant Genet. Resources, 1985), and testa-impermeable germination inhibitors have been noted in Xanthium [Asteraceae] (Porter and Wareing, 1974).

Differences in the degree of staining within a seed lot probably were not the result of differences in embryo vigor. An indicator of seed vigor is speed of germination (Geneve, 2005), and the intensity of staining would be expected to be greater as seed vigor increases (AOSA, 2000). Although this clearly held true for $C$. floridana-there was nearly a one-to-one relationship because almost all viable seeds germinated within $7 \mathrm{~d}$ and most viable seeds stained pink or redthis was not the case for the other species. Stored, nonpreconditioned seeds of C. basalis, C. leavenworthii, and C. lanceolata were much more vigorous than their corresponding fresh seeds based on the percentage of viable seeds that germinated by $7 \mathrm{~d}(C$. basalis, $54.4 \%$ versus $2.7 \%$; C. leavenworthii, $91.8 \%$ versus $40.4 \%$; C. lanceolata, $93.2 \%$ versus $0 \%$ ). However, these differences in vigor were not manifested as correspondingly higher percentages of viable embryos that stained pink or red in pregermination $\mathrm{TZ}$ testing. For C. basalis and C. leavenworthii, these percentages were similar within a species for stored and fresh, nonpreconditioned seeds (C. basalis, $34.1 \%$ versus $39.1 \%$; C. leavenworthii, $14.4 \%$ versus $9.9 \%$ ). Although the percentage of viable embryos that stained pink or red in pregermination TZ testing of stored, nonpreconditioned seeds of $C$. lanceolata was greater than that for fresh seeds $(31.3 \%$ versus $18.6 \%$ ), the difference was much less than would be expected for the substantial difference in vigor. Lack of staining in any species was not the result of deep dormancy (Vivrette, 1995) because all viable excised embryos of $C$. basalis, $C$. lanceolata, and $C$. leavenworthii germinated (Tables 1 and 2).

Other methods of assessing seed viability. The excised embryo germination test in light was an extremely accurate, uniform method for determining percentage viability of $C$. basalis, $C$. lanceolata, and $C$. leavenworthii seeds. All viable excised embryos of $C$. basalis, C. lanceolata, and C. leavenworthii germinated under light (Tables 1 and 2) with all $\mathrm{CsV}$ less than 0.2. Light is an important factor because Rukuni et al. (2006) reported that optimal germination of all prevariety 


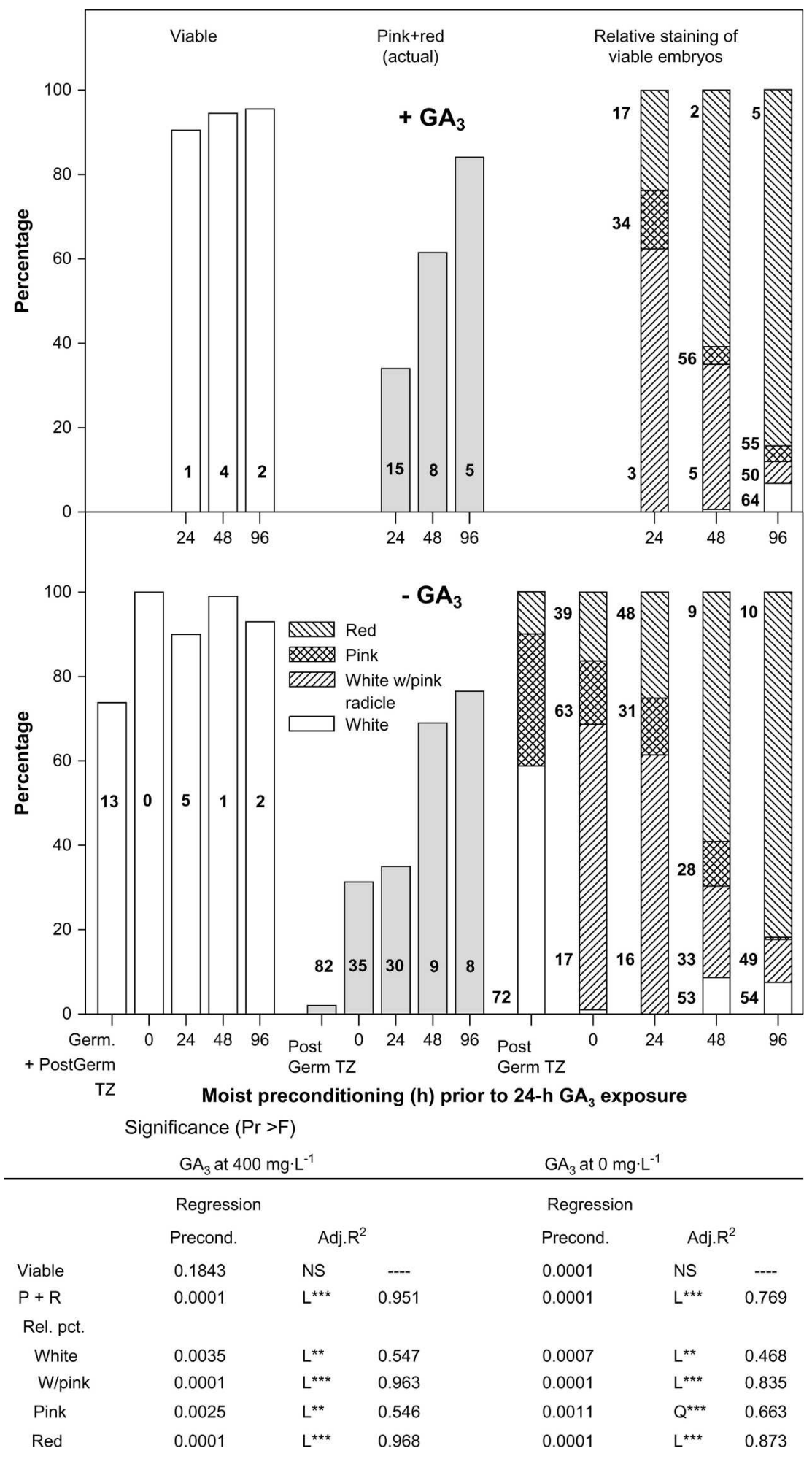

Fig. 6. Moist preconditioning (water only) and gibberellic acid $\left(\mathrm{GA}_{3}\right)$ effects on the pregermination tetrazolium (TZ) test to estimate percentage viability of stored, intact seeds of Coreopsis lanceolata. Seeds were exposed to $\mathrm{GA}_{3}$ at 0 or $400 \mathrm{mg} \cdot \mathrm{L}^{-1}$ for $24 \mathrm{~h}$ after moist preconditioning for 24,48 , or $96 \mathrm{~h}$, and then subjected to $\mathrm{TZ}$ testing. A germination test $(67.8 \%$; coefficient of variation $=16.9)$ plus postgermination test of nongerminated seeds was included as a standard method of calculating percentage viability; this treatment was not included in the regression analyses. Seeds were from a different lot or source than in Figure 5. Estimated percentage viability based on a preliminary pregermination TZ test using the AOSA (2000) protocol (seeds cut through the cotyledonary end essential tissues stained pink to red) was $66.7 \%(\mathrm{n}=15)$. Coefficients of variation less than 100 are shown within or to the immediate left of each bar. germplasm of these species occurred with light. Given the accuracy and uniformity of the excised embryo test, the likelihood of a false-positive or -negative, that is, experimental error, is nil for these three Coreopsis species. Although radicle emergence was defined as a positive result for the embryo excision test, redefining a positive test as development of a normal seedling would have minimal impact on experimental error with the main disadvantage being the additional time required for the test. Regardless, removing experimental error as a source of nonuniformity among replications in the excised embryo germination test should ensure that percentage viability results will fall well within AOSA tolerance levels for germination tests (AOSA, 2004) provided that the seeds tested accurately represent the seed lot. An embryo excision test was not conducted for $C$. floridana, but based on results with the other three Coreopsis species and those of Rukuni et al. (2007b), we expect that an excised embryo germination test of $C$. floridana would be as uniform and accurate as with the other three species. This test must be conducted under light as well because Rukuni et al. (2007b) noted that $100 \%$ germination of viable $C$. floridana excised embryos only occurred under light.

Germinating seeds in a soilless medium or field soil substantially underestimated percentage viable seeds of all four Coreopsis species although emergence tests lasted twice as long as standard germination tests (Table 3 ). Moreover, results usually were highly variable because most $\mathrm{CsV}$ ranged from 20.2 to 120 . Poor emergence of $C$. lanceolata might have been the result of thermoinhibition (Rukuni et al., 2006), but that possibility is less clear for C. basalis and C. leavenworthii. Rukuni et al. (2006) noted that germination of $C$. basalis and C. leavenworthii declined above $25^{\circ} \mathrm{C}$, but $C$. basalis germination under north Florida field conditions typically occurs in late August and September (J. G. Norcini, unpublished observation), and no thermoinhibition of C. leavenworthii was observed by Kabat et al. (2007). Seeds of $C$. floridana were exposed to nonoptimal germination temperatures (Norcini and Aldrich, 2005), which might have inhibited emergence.

\section{Conclusions}

Precise testing methods that yield uniform results are critical for evaluating the quality of premium value seeds of regionally and locally adapted native species. When 10 s to 100 s of kilograms of seeds costing $\$ 110$ per kilogram or more are purchased for roadside, reclamation, or restoration projects, even small errors in viability estimates can have substantial economic impacts for the producer and end user. Such potential economic impact warrants the use of the embryo excision germination test, although it might be more costly and take longer to conduct than a pregermination $\mathrm{TZ}$ test. 


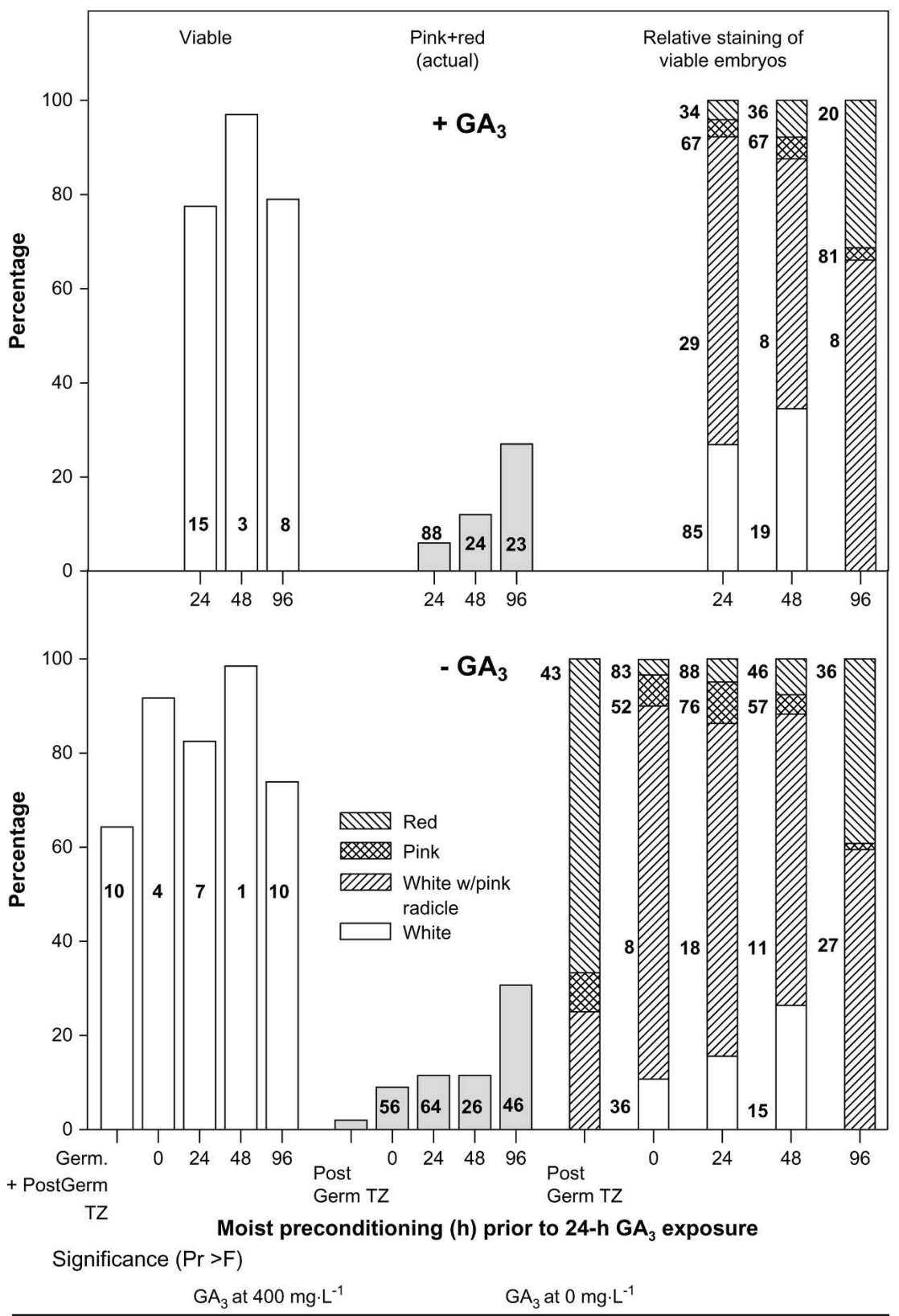

\begin{tabular}{|c|c|c|c|c|c|c|}
\hline \multirow[b]{3}{*}{ Viable } & \multicolumn{3}{|c|}{ Regression } & \multicolumn{3}{|c|}{ Regression } \\
\hline & Precond. & \multicolumn{2}{|c|}{ Adj. $R^{2}$} & Precond. & \multicolumn{2}{|c|}{ Adj. $R^{2}$} \\
\hline & 0.0028 & NS & ---- & 0.0001 & NS & --- \\
\hline$P+R$ & 0.0027 & $\mathrm{~L}^{* * *}$ & 0.688 & 0.0189 & $Q^{* * *}$ & 0.447 \\
\hline \multicolumn{7}{|l|}{ Rel.pct. } \\
\hline White & 0.0016 & $\mathrm{~L}^{*}$ & 0.386 & 0.0042 & $Q^{*}$ & 0.379 \\
\hline W/pink & 0.2639 & NS & --- & 0.0879 & $L^{*}$ & 0.340 \\
\hline Pink & 0.5913 & NS & --- & 0.0751 & $L^{*}$ & 0.274 \\
\hline Red & 0.0002 & $\mathrm{~L}^{* * *}$ & 0.759 & 0.0001 & $Q^{* * *}$ & 0.773 \\
\hline
\end{tabular}

Fig. 7. Moist preconditioning (water only) and gibberellic acid $\left(\mathrm{GA}_{3}\right)$ effects on the pregermination tetrazolium (TZ) test to estimate percentage viability of fresh (less than 2 weeks after harvest), intact seeds of Coreopsis leavenworthii. Seeds were exposed to $\mathrm{GA}_{3}$ at 0 or $400 \mathrm{mg} \cdot \mathrm{L}^{-1}$ for $24 \mathrm{~h}$ after moist preconditioning for 24,48 , or $96 \mathrm{~h}$, and then subjected to TZ testing. A germination test $(61.5 \%$; coefficient of variation $=10.3$ ) plus postgermination test of nongerminated seeds was included as a standard method of calculating percentage viability; this treatment was not included in the regression analyses. Estimated percentage viability based on a preliminary pregermination TZ test using the AOSA (2000) protocol (seeds cut through the cotyledonary end; essential tissues stained pink to red) was $77.8 \%(n=18)$. Coefficients of variation less than 100 are shown within or to the immediate left of each bar.
The embryo excision germination test in light was the most accurate and uniform method of determining viability of prevariety germplasm of $C$. basalis, C. lanceolata, $C$. leavenworthii, and probably $C$. floridana. First, dormancy, which can be a significant factor affecting germination of native species as noted previously, is not an issue because all viable excised embryos of $C$. basalis, $C$. floridana, C. lanceolata, and C. leavenworthii germinate in light (Table 2; Norcini and Aldrich, 2005; Rukuni et al., 2007b). Because all viable excised embryos germinate, variability among replications is minimal (Tables 1 and 2). Second, the excised embryo germination test was more accurate than TZ tests. For example, higher percentage viability values for $C$. lanceolata and $C$. leavenworthii were obtained with the excised embryo germination test than for the pregermination TZ test of excised embryos (Table 2) although staining of viable excised embryos should have been same as if seeds were cut per the AOSA TZ protocol for Asteraceae seeds (AOSA, 2000). Also, percentage viability results for $C$. basalis were not always consistent when using the $\mathrm{TZ}$ test as exemplified by results in Table 3 . Third, the embryo excision germination test requires about the same level of manual dexterity needed for the AOSA TZ test and the same skill level required to interpret a standard germination test. We acknowledge that cutting seeds through the cotyledonary end would improve staining and make the TZ test easier to interpret, but the potential for experimental error is still greater with the $\mathrm{TZ}$ test than for the excised embryo germination test as we noted previously. The substantial training and experience required to accurately determine viability based largely on the degree of TZ staining of essential embryo structures, which can vary by species, is widely acknowledged as a major challenge in TZ testing (AOSA, 2000).

However, if using the TZ test for determining viability of these native Coreopsis species, the use of intact seeds provides a potentially labor-saving alternative to the standard practice of laterally cutting seeds through the cotyledonary end before the TZ test. Seeds do not need to be individually oriented to make the necessary cut, no training is required to identify the cotyledonary end of seeds, and the seed technologist can use the most convenient method to properly extract the embryo after the TZ test. Clearing the seedcoat to observe embryo staining, thereby reducing labor, is not an option because the Coreopsis seedcoat is too thick to be cleared (S. Dammen, personal communication) and turgidity would be difficult to determine.

One problem that we noted was the relatively high degree of variability (i.e., high $\mathrm{CsV}$ ) when germination rates were low as a result of dormancy or poor quality and in postgermination $\mathrm{TZ}$ testing when the percentages of dormant seeds were low Given the premium values of these seeds, we suggest that sample sizes be increased to 


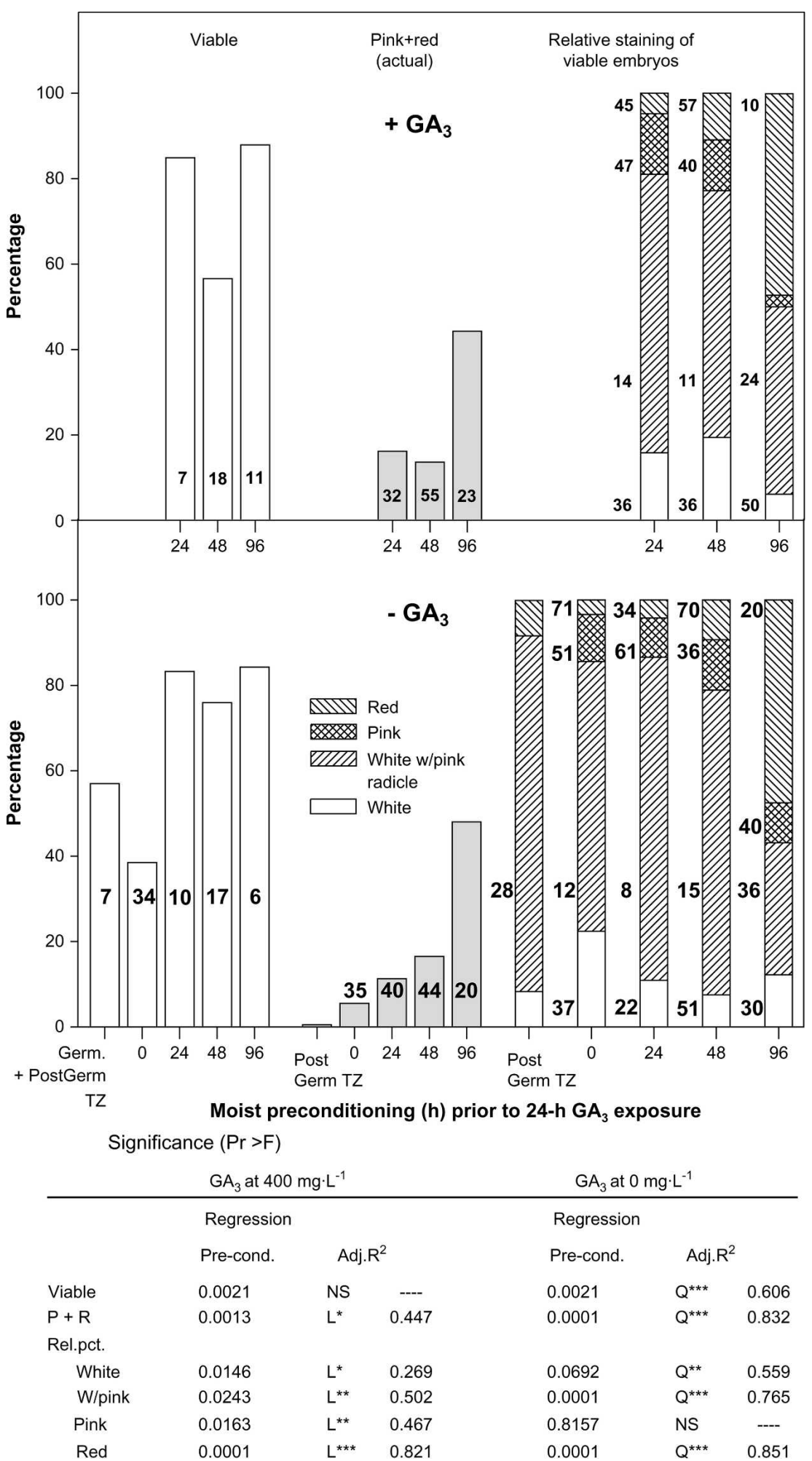

Fig. 8. Moist preconditioning (water only) and gibberellic acid $\left(\mathrm{GA}_{3}\right)$ effects on the pregermination tetrazolium (TZ) test to estimate percentage viability of stored, intact seeds of Coreopsis leavenworthii. Seeds were exposed to $\mathrm{GA}_{3}$ at 0 or $400 \mathrm{mg} \cdot \mathrm{L}^{-1}$ for $24 \mathrm{~h}$ after moist preconditioning for 24,48 , or 96 $\mathrm{h}$, and then subjected to TZ testing. A germination test $(53.0 \%$; coefficient of variation $=9.0)$ plus postgermination test of nongerminated seeds was included as a standard method of calculating percentage viability; this treatment was not included in the regression analyses. Seeds were from a different lot or source than in Figure 7. Estimated percentage viability based on a preliminary pregermination TZ test using the AOSA (2000) protocol (seeds cut through the cotyledonary end; essential tissues stained pink to red) was $13.3 \%(n=15)(60.0 \%$ of embryos were white with a pink radicle tip). Coefficients of variation less than 100 are shown within or to the immediate left of each bar. reduce variability among replications if seeds are thought be relatively dormant. Although increasing sample size increases testing costs, repeating germination tests because variability among replications is great enough to exceed AOSA tolerance levels (AOSA, 2000) is probably more costly.

\section{Literature Cited}

Aarssen, L.W. and S.M. Burton. 1990. Maternal effects at four levels in Senecio vulgaris (Asteraceae) grown on a soil nutrient gradient. Amer. J. Bot. 77:1231-1240.

Andersson, L. and P. Milberg. 1998. Variation in seed dormancy among mother plants, populations, and years of seed collection. Seed Sci. Res. 8:29-38.

Association of Official Seed Analysts. 2000. Tetrazolium testing handbook, contribution no. 29 to the handbook on seed testing, first revision. Peters, J. (ed.). Assn. Offic. Seed Analysts, Stillwater, OK.

Association of Official Seed Analysts. 2004. Rules for testing seeds. Assn. Offic. Seed Analysts, Lincoln, NE.

Baskin, C.C. and J.M. Baskin. 1998. Seeds: Ecology, biogeography, and evolution of dormancy and germination. Academic Press, San Diego, CA.

Bender, M.H., J.M. Baskin, and C.C. Baskin. 2003. Seed germination ecology of Polymnia canadensis (Asteraceae), a monocarpic species of the North American temperate deciduous forest. Plant Ecol. 168:221-253.

Booth, D.T. and T.A. Jones. 2001. Plants for ecological restoration: A foundation and a philosophy for the future. Native Plants J. $2: 12-20$.

Borthwick, H.A. and W.W. Robbins. 1928. Lettuce seed and its germination. Hilgardia 3:275305.

Carpenter, W.J. and E.R. Ostmark. 1992. Growth regulators and storage temperature govern germination of coreopsis seed. HortScience 27: 1190-1193.

Carpenter, W.J. and E.R. Ostmark. 2007. Corrigendum. HortScience 42:748.

Czarnecki D.M., II, J.G. Norcini, and Z. Deng. 2007. Phenotypic diversity of Coreopsis leavenworthii (Asteraceae). Native Plants J. 8:45-56.

Dehgan, B. and J.G. Norcini. 2006. Treatment and germination of Florida native wildflower seeds for commercial production and natural landscaping. Final report to the Florida Wildflower Advisory Council. 29 Nov. 2006. <http://nfrec. ifas.ufl.edu/norcini/Publications/DehganNorciniFinalReportJan2006.pdf $>$.

Fenner, M. 1991. The effects of the parent environment on seed germinability. Seed Sci. Res. 1:75-84.

Flemion, F. 1948. Reliability of the excised embryo method as a rapid test for determining germinative capacity of dormant seeds. Contrib. Boyce Thomp. Inst. 15:229-241.

Forsyth, C. and N.A.C. Brown. 1982. Germination of the dimorphic fruits of Bidens pilosa $\mathrm{L}$. New Phytol. 90:151-164.

Geneve, R.L. 2005. Vigor testing in flower seeds, p. 311-332. In: McDonald, M.B. and F.Y. Kwong (ed.). Flower seeds: Biology and technology. CAB Intl., Wallingford, UK

Gutormson, T.J. 2002. Improving testing methods for native seeds. Seed Technol. 24:7-8.

Heit, C.E. 1947. Physiology of germination. New York (Geneva) Agric. Expt. Station Sixty-Fifth Annu. Rpt. p. 58-59. 
Houseal, G. and D. Smith. 2000. Source-identified seed: The Iowa roadside experience. Ecol. Restor. 18:173-183.

Idaho Dept. of Agriculture. 1993. Admin. code IDAPA 02.06.01, rules governing the pure seed law. 4 Sept. 2007. <http://adm.idaho.gov/admin rules/rules/05codearchives/IDAPA\%2002/0601. pdf $>$.

Intl. Board for Plant Genet. Resources. 1985. Chapter 17: General approaches to promoting seed germination. In: Ellis, R.H., T.D. Hong, and E.H. Roberts (ed.). Handbook of seed technology for genebanks - Volume II. Compendium of specific germination information and test recommendations. 18 Dec. 2007. < http://www.bioversity international.org/publications/Web_version/52/ch02. htm\#CHAPTER \%2017.\%20GENERAL\%20 APPROACHES\%20TO\%20PROMOTING\% 20SEED $\% 20$ GERMINATION>.

Kabat, S.M., J.G. Norcini, and B. Dehgan. 2007. Effect of light and temperature on germination of Leavenworth's coreopsis (Coreopsis leavenworthii). Native Plants J. 8:236-247.

Kaye, T.N. 2002. Propagation methods and preliminary evidence of the importance of population size for Aster vialis, a rare plant of western Oregon forests. Inst. Appl. Ecol., Corvallis, OR.

Lakon, G. 1942. Topographischer Nachweis der Keimfähigkeit der Getreidefrüchte durch Tetrazoliumsalze. Ber. Deutsch. Bot. Ges. 60:299-305.

Naqvi, H.H. and G.P. Hanson. 1980. Recent advances in guayule seed germination procedures. Crop Sci. 20:501-504.

Nebraska Dept. of Agriculture, Bureau of Plant Industry. 1997. Laws and regulations: Seed law and related statutes. 4 Sept. 2007. <http://www. agr.state.ne.us/regulate/bpi/actc.htm $>$.

Norcini, J.G. and J.H. Aldrich. 2005. Native coreopsis species-Germination and after-ripening studies. Fifth Annual Native Seed Quality Con- ference, 23-24 Feb. 2005, Omaha, NE. 15 July 2008. <http://nfrec.ifas.ufl.edu/norcini/ppt/ Coreopsis_AR-Germ_Norcini-NSQC2005.pdf>.

Norcini, J.G. and J.H. Aldrich. 2007. Storage effects on dormancy and germination of native tickseed species. HortTechnology 17:505512.

Norcini, J.G., J.H. Aldrich, and F.G. Martin. 2004. Harvest season influences fertilizer effects on seed production of lanceleaf coreopsis. J. Environ. Hort. 22:229-233.

Norcini, J.G., J.H. Aldrich, and F.G. Martin. 2006. Harvest season and fertilizer effects on seed production of Leavenworth's coreopsis. J. Environ. Hort. 24:63-67.

Porter, N.G. and P.F. Wareing. 1974. The role of oxygen permeability of the seed coat in the dormancy of seed of Xanthium pennsylvanicum Wallr. J. Expt. Bot. 25:583-594.

Roach, D.A. and R.D. Wulff. 1987. Maternal effects in plants. Annu. Rev. Ecol. Syst. 18:209-235.

Ruiz de Clavijo, E. 2005. The reproductive strategies of the heterocarpic annual Calendula arvensis (Asteraceae). Acta Oecol. 28:119126.

Rukuni, D., J.G. Norcini, and D.J. Cantliffe. 2006. Seed dormancy and germination of Coreopsis species. IVth Intl. Symp. and 8th Natl. Symp. on Seed, Transplant and Stand Establishment of Hort. Crops: Translating Seed and Seedling Physiol. into Technol., San Antonio, TX, 3-6 Dec. 2006 (poster).

Rukuni, D., J.G. Norcini, and D.J. Cantliffe. 2007a. Gibberellin requirement for Coreopsis species seed germination. HortScience 42:910. (abstr.).

Rukuni, D., J.G. Norcini, D.J. Cantliffe, and B.A. Hauser. 2007b. Morphology and anatomy of the coreopsis (Asteraceae) achene. Plant Sci. Symp.-Translational Seed Biology: From
Model Systems to Crop Improvement, Davis, CA, 17-20 Sept. 2007 (abstr.).

Sharma, H.P. 1979. In vitro culture of dormant embryos of Calliopsis basalis Dietr. Z. Pflanzenphysiol. 91:45-48.

Smith, E.B. 1975. The chromosome numbers of North American Coreopsis with phyletic finterpretations. Bot. Gaz. (Crawfordsville) 136:78-86.

South Dakota Statutes. 2007. Seed standards and labeling, chapter 38-12A-2. 4 Sept. 2007. $<$ http://legis.state.sd.us/statutes/DisplayStatute. aspx Type $=$ Statute $\&$ Statute $=38-12 \mathrm{~A}-2>$.

Southeast Regional Climate Center. 2001. Historical climate summaries for Florida. South Carolina Dept. of Natural Resources, Columbia, SC. 19 Feb. 2001. <http://www.sercc.com/ climateinfo/historical/historical_fl.html $>$.

Tadesse, M., D.J. Crawford, and E.B. Smith. 1995 Comparative capitular morphology and anatomy of Coreopsis L. and Bidens L., including a review of generic boundaries. Brittonia 47: 61-91.

U.S. Dept. of Agriculture, Natural Resources Conservation Service. 2006. Search results for scientific name $=$ Coreopsis. The PLANTS database. Natl. Plant Data Ctr., Baton Rouge, LA. 8 Mar. 2007. <http://plants.usda.gov/java/ nameSearch?mode $=$ Scientific + Name \&keyword query $=$ Coreopsis $>$.

Vivrette, N. 1995. Pre-treatment of dormant seeds prior to TZ test. Laboratory notes. Seed Technologist Newsl. 69(3):66.

White, P.R. 1963. The cultivation of animal and plant cells. 2nd Ed. The Ronald Press Co., New York, NY.

Wulff, R.D. 1986. Seed size variation in Desmodium paniculatum: II. Effects on seedling growth and physiological performance. J. Ecol. 74:99-114. 